\title{
Brain-Derived Neurotrophic Factor and Its Intracellular Signaling Pathways in Cocaine Addiction
}

\author{
M. Corominas C. Roncero M. Ribases X. Castells M. Casas \\ Psychiatry Service, Vall d'Hebron Hospital, Psychiatry Department of the Universitat Autònoma de Barcelona, \\ Barcelona, Spain
}

\section{Key Words}

Cocaine addiction $\cdot$ Psychostimulant $\cdot$ Brain-derived neurotrophic factor $\cdot$ Extracellular signal-regulated protein kinase $\cdot$ Phosphatidylinositol 3-kinase $\cdot$ Sensitization . Conditioning $\cdot$ Craving $\cdot$ Relapse

\begin{abstract}
Cocaine addiction is one of the severest health problems faced by western countries, where there is an increasing prevalence of lifelong abuse. The most challenging aspects in the treatment of cocaine addiction are craving and relapse, especially in view of the fact that, at present, there is a lack of effective pharmacological treatment for the disorder. What is required are new pharmacological approaches based on our current understanding of the neurobiological bases of drug addiction. Within the context of the behavioral and neurochemical actions of cocaine, this paper considers the contribution of brain-derived neurotrophic factor (BDNF) and its main intracellular signaling mechanisms, including mitogen-activated protein kinase/extracellular signal-regulated protein kinase (MAPK/ERK) and phosphatidylinositol 3-kinase (PI3K), in psychostimulant addiction. Repeated cocaine administration leads to an increase in BDNF levels and enhanced activity in the intracellular pathways (PI3K and MAPK/ERK) in the reward-related brain areas, which applies especially several days following withdrawal.
\end{abstract}

It has been hypothesized that these neurochemical changes contribute to the enduring synaptic plasticity that underlies sensitized responses to psychostimulants and drug-conditioned memories leading to compulsive drug use and frequent relapse after withdrawal. Nevertheless, increased BDNF levels could also have a role as a protection factor in addiction. The inhibition of the intracellular pathways, ERK and $\mathrm{PI} 3 \mathrm{~K}$, leads to a disruption in sensitized responses and conditioned memories associated with cocaine addiction and suggests new, potential therapeutic strategies to explore in the dependence on psychostimulants.

Copyright $\odot 2007$ S. Karger AG, Basel

\section{Introduction}

Cocaine consumption continues to be an important public health hazard, increasing in prevalence and use in western countries. Addiction to psychostimulants is a chronic disorder, characterized by craving, an intense desire to experience the effects of a psychoactive substance and frequent relapse, even after prolonged drug-free periods, when all withdrawal symptoms have receded [1-3]. Despite various strategies for treatment that include antidepressant pharmacotherapy, dopaminergic agonists, antiepileptics or lithium, one of the main problems related to psychostimulant addiction is the absence of an

\section{KARGER}

Fax +4161306 1234 E-Mail karger@karger.ch www.karger.com
(C) 2007 S. Karger AG, Basel

0302-282X/07/0551-0002\$23.50/0

Accessible online at:

www.karger.com/nps
Dr. Margarita Corominas

Psychiatry Service, Vall d'Hebron Hospital

Escola d'Enfermeria building, 5th floor, Pg. Vall d'Hebron, 119-129

ES-08035 Barcelona (Spain)

Tel. +349348942 94, Fax +34 9348945 87, E-Mail mcoromin@vhebron.net 
effective pharmacotherapeutic agent for its treatment [4]. Thus, new therapeutic approaches, based on our current understanding of the neurobiological bases of drug addiction, are required.

Over the last few years, several lines of research have suggested that chronic drug exposure causes long-lasting neurochemical and cellular adaptations that result in enduring neuroplastic changes in brain circuitry, and which underlie compulsive drug consumption and relapse, even after long periods of abstinence [5-7]. Attention has mainly been focused on the effects of various drugs of abuse on cortical and subcortical areas, including the mesolimbic and mesocortical systems, comprising dopamine neurons in the ventral tegmental area (VTA), their projection to the nucleus accumbens (NAc), amygdala and other forebrain regions $[8,9]$. Dopamine-dependent synaptic plasticity in the dorsal striatum has also been involved mostly in the late stages of addiction $[8,10]$. The role of glutamatergic neurotransmitter systems and interaction between dopamine and glutamate in determining the neuroplastic changes related to psychostimulant consumption warrant attention $[11,12]$. At the molecular level, the effects induced by chronic drug consumption also involve several intracellular signaling pathways [13, 14] that lead to sensitization to drug effects [9] and modification in the learning and memory circuitry related to addiction [8]. Despite recent advances, however, the molecular bases of cocaine addiction have been only partially elucidated.

Recent evidence suggests that neurotrophins, such as brain-derived neurotrophic factor (BDNF) and its intracellular signaling pathways, are also involved in neuroadaptive changes in the dopaminergic or glutamate systems that underlie psychostimulant abuse and dependence [15-21]. BDNF is a member of the nerve growth factor family, a group of secreted homodimeric proteins, isolated and characterized for the first time in 1982 [22]. The BDNF signal transduction is mediated by binding to two different transmembrane receptors: the high-affinity tyrosine kinase receptor B (Ntrk2 or TrkB) which specifically recognizes BDNF [23], and the low-affinity p75 neurotrophin receptor [24]. Both of these colocalize and modulate the neuron response to this neurotrophin. The BDNF binding to the TrkB-specific receptor triggers a ligand-dependent dimerization of the receptor, the autophosphorylation of specific intracellular tyrosine residues, and the activation of three different signal transduction cascades. These include the phosphatidylinositol 3-kinase (PI3K), the mitogen-activated protein kinase/ extracellular signal-regulated protein kinase (MAPK/
ERK), and the phospholipase $\mathrm{C} \gamma$ cascades [25-27]. Some of these intracellular signaling mechanisms can also be activated through stimulation of dopamine and glutamate neurotransmission $[21,28]$, and there is evidence that cross-talk between those pathways may potentiate synaptic plasticity in drug addiction.

BDNF is expressed in several areas of the central nervous system, including the amygdala $[29,30]$, the striatum [31], the prefrontal cortex [32], and its specific receptor TrkB is expressed in all mesencephalic dopaminergic neurons [33]. All these regions are involved in drug-induced neuronal responses. BDNF is a key element in the survival and differentiation of the dopaminergic system [34]. In the mature central nervous system, BDNF [3538] and its intracellular pathways, MAPK/ERK [39-42] and PI3K $[43,44]$, play an essential role in modulating activity-dependent neuronal plasticity. In fact, these neurochemical systems are required to induce long-term potentiation (LTP), the basic mechanism of learning and memory that allows the external world to become encoded and stored as persistent molecular and structural modifications.

The aim of the present review is to examine the evidence supporting the involvement of the BDNF and its intracellular pathways in the neural mechanisms that underlie the development of psychostimulant addiction, that is to say, sensitization and conditioned drug responses, craving during withdrawal and subsequent relapse. The identification of new neurobiological substrates in cocaine addiction is of considerable interest as it could provide new targets for the treatment of drug addiction.

\section{BDNF and Acute Psychostimulant Effects}

Several studies developed in the early 1990s tried to assess the behavioral and neurochemical effects of exogenous BDNF in different dopaminergic regions, and its interaction with a posterior single dose of psychostimulants. In adult rats, repeated BDNF infusions into the pars compacta of the substantia nigra $(\mathrm{SN})$ potentiated the contraversive rotation behavior induced by posterior psychostimulant (amphetamine) administration. At the same time, neostriatal levels of dopamine metabolites, homovanillic acid and 3,4-dihydroxyphenylacetic acid, were found to be increased in the BDNF-infused brain hemisphere. These behavioral and neurochemical effects suggested that BDNF is able to act on adult dopamine neurons in vivo, enhancing activity of nigrostriatal circuits and dopamine release $[15,45]$. Some years later, oth- 
er studies assessed the effect of exogenous BDNF administration into two different regions of the mesolimbic dopaminergic system, the NAc and VTA, and its influence on locomotor activity induced by posterior cocaine administration. The results showed that cocaine challenge induced a significant enhancement of locomotor activity in mice when administered the day after repeated intraNAc and intra-VTA BDNF treatment. Therefore, BDNF enhanced the initial stimulant effect of cocaine [19]. In contrast, other authors have reported that although BDNF induced an increased behavioral activity when administered repeatedly into the VTA, no further increased activity was seen after subsequent cocaine injection [16]. Collectively, these data showed that administration of BDNF in nigrostriatal and mesolimbic dopamine pathways potentiates psychostimulant effects, increasing anatomically specific dopamine-dependent behavior and neurochemical turnover in those brain regions.

Based on the fact that the sole use of psychostimulants is able to enhance dopamine transmission in the mesocorticolimbic regions, various experimental studies have assessed the effect of cocaine on BDNF expression in these areas of the brain. Although an early study reported no effect of acute cocaine on BDNF levels in the VTA, SN and hippocampus [16], a recent report revealed an enhancement in the expression of mRNA encoding BDNF in the rat NAc shell, but not in the core, induced by acute cocaine administration [18]. The enhanced BDNF in this specific striatal area is consistent with the role of the medioventral NAc compartment, the shell, the site of action for natural rewards such as food [46] and psychoactive drugs [47]. In the prefrontal and frontal cortices, a transient increase in the BDNF mRNA expression 2-4 $\mathrm{h}$ after a single cocaine injection was also reported [48]. The increased expression of BDNF in some brain areas after acute psychostimulant administration is in accordance with the ability of cocaine to induce activity-dependent changes in the expression of BDNF as an immediate early gene [49]. The role of psychostimulants on BDNF expression has been confirmed using heterozygous $\mathrm{BDNF}+/-$ knockout mice, which display half of the wild-type BDNF levels and provide a good model wherein to study the lifelong variation at the BDNF locus. Despite the fact that heterozygous $\mathrm{BDNF}+/-$ mice showed results in locomotor activity equivalent to wild-type $\mathrm{BDNF}+/+[50], \mathrm{BDNF}$ heterozygous animals displayed less locomotion than the wild-type animals after a single cocaine injection [51].

\section{BDNF and Cocaine-Induced Sensitization}

It is now well established that some drugs of abuse, such as cocaine, administrated intermittently and repeatedly, can produce an enhancement of some drug-related responses, defined as sensitization [52]. In animal models, sensitization can be measured by assessing the increase in locomotor behavior after repeated cocaine or amphetamine administration. The effects of a well-established sensitization are long-lasting, and can be observed several weeks, or even 1 year, after the last exposure to the drug $[9,53]$. As Robinson and Berridge $[9,53]$ hypothesized in their incentive sensitization theory, sensitization is thought to underlie important aspects of vulnerability to drug addiction, the craving during withdrawal and relapse in humans. In rodents, sensitization was shown to enhance predisposition to psychostimulant self-administration [54] and facilitate the reinstatement of drugs after extinguished self-administration [55]. Moreover, there is a possibility that sensitization could contribute to psychotic symptomatology (e.g. drug-induced paranoia) among psychostimulant abusers and addicts, and even to the risk of schizophrenia in vulnerable individuals [56]. Recent research has suggested that BDNF could play some part in the neuronal changes that underlie sensitization following repeated psychostimulant administration.

In an early study, BDNF was infused for 2 weeks into two brain areas, the NAc and VTA, before the rats underwent a treatment of cocaine sensitization. BDNF-treated animals showed a progressive increase in locomotor activity after repeated intra-NAc and intra-VTA cocaine injections, suggesting that BDNF into mesolimbic dopamine areas may facilitate the development of sensitization to subsequent cocaine doses [19]. Recent experimental designs have studied the neurochemical changes underlying the behavioral effects of repeated cocaine treatment. The increase in locomotor activity and sensitization induced by repeated doses of cocaine was associated with enhanced levels of mRNA encoding BDNF in the rat NAc shell, but not in the core, nor in the hippocampus [18]. These results were in agreement with the discrete roles of the NAc shell and core and the preferential involvement of the shell in the expression of cocaine sensitization [57]. Locomotor sensitization to repeated cocaine administration was also studied in heterozygous BDNF knockout mice compared with their wild-type littermates. Although there were no differences in locomotor activity between groups at baseline, BDNF knockout mice were less sensitive to the locomotor stimulant effects 
of cocaine and showed a delay in the development of sensitization [19]. Together, these results suggest that the changes in BDNF expression, after repeated cocaine administration, especially in two areas of the reward circuitry, the VTA and NAc shell, could play a role in the development of sensitizing effects of this drug of abuse (fig. 1).

It has been suggested that the increase in BDNF expression induced by cocaine is mediated through dopamine $D_{1}$ receptor activation [58]. In turn, it seems that BDNF can strengthen cocaine-induced behavioral sensitization by controlling the expression of specific genes, such as the $\mathrm{D}_{3}$ dopamine receptor. One of the functions of $\mathrm{D}_{3}$ receptor is to modulate the actions of $\mathrm{D}_{1}$ and $\mathrm{D}_{2}$ postsynaptic dopamine receptors [59]. $\mathrm{D}_{3}$ expression is elevated in the striatum in chronic cocaine abuse [60]. Using lesions or mice lacking BDNF, it has been shown that $\mathrm{BDNF}$ from dopamine neurons is crucial in triggering dopamine $\mathrm{D}_{3}$ receptor expression $[48,61,62]$, and the induction of $\mathrm{D}_{3}$ occurs mostly in the core of the NAc and in the dorsal striatum, two areas where $\mathrm{D}_{3}$ is normally almost totally absent $[61,62]$. Pharmacological treatment using highly selective $\mathrm{D}_{3}$ ligands specifically reduces responses associated with cocaine consumption $[63,64]$. These findings suggest that BDNF may have a role in determining some pathophysiological conditions such as drug addiction $[60,65]$.

On the other hand, BDNF can also act as a neuroprotection factor in drug addiction activating some homeostatic mechanisms that can counteract the effects of the chronic drug use. In fact, BDNF is able to induce the expression of neuropeptide $\mathrm{Y}$ and preprodynorphin in the striatum and NAc $[62,66]$ and their increase may attenuate the effects of addictive drugs, whereas a decrease potentiates the effects of the drugs [14]. It is well known that BDNF [67] has a role in neuronal survival by providing the necessary neuronal trophic support and having a neuroprotective effect on pathological conditions, such as mood disorder [68, 69]. According to these data, the increased expression of BDNF in cocaine addiction can enhance neuronal resilience, especially in reward-related areas, thus counteracting the pathological effects of the repeated drug consumption.

\section{BDNF and Conditioned Responses to Cocaine}

Environmental stimuli that are closely associated in time and space with the effects of drugs of abuse can acquire secondary reinforcing properties through a process of Pavlovian conditioning. The conditioned stimuli have in themselves the ability to elicit the emotional responses that were induced by the drug during active consumption, and maintain drug-seeking behavior and relapse, even after long-term abstinence [70]. BDNF is a growth factor involved in synaptic plasticity $[36,37,71,72]$ and in cellular events, such as LTP $[35,38]$, thought to underlie contextual learning in the hippocampus [73] and conditioned responses in the amygdala [30, 74]. Based on its functional ability, it has been suggested that the increased BDNF released during repeated psychostimulant intake might also have a role in the neuronal mechanism that underlies the conditioned responses to psychostimulants.

In an early study, Horger et al. [19] assessed the ability of BDNF to modify the reward-related properties of the cocaine-associated stimuli in rodents. Intra-NAc BDNF infusions strengthened the ability of a stimulus to act as a conditioned reinforcer and also increased the cocaineinduced response to the conditioned reinforcer. The increased cocaine effects in BDNF-treated rats persisted for more than a month after the BDNF infusions had finished. This report supports the hypothesis that BDNF promotes long-lasting changes in the mesolimbic dopamine system, activating mechanisms of associative learning that underlie the persistent addictive behavior that endures long after withdrawal. These results were later confirmed by a classic Pavlovian procedure that showed that mice repeatedly receiving cocaine in a particular environment showed hyperactivity after subsequent exposure to the drug-paired environment. The increased conditioned responses were associated with enhanced mRNA BDNF expression in the VTA which, in turn, modulates the expression of $\mathrm{D}_{3}$ receptor in the NAc. Hyperactivity was not elicited by repeated cocaine administration or exposure to a new place, and it was assumed that the conditioned stimuli progressively acquired an emotional component associated with incentive and motivational properties [75]. The role of BDNF in drug-associated stimuli was further confirmed in heterozygous knockout mice using a conditioned place preference $(\mathrm{CPP})$ paradigm. BDNF+/- mice showed attenuated effects of cocaine reward and a decreased ability to learn a new association between the drug and the place where it was administered [51]. Overall, these results suggest that BDNF modulates synaptic morphology and plasticity underlying the learning processes $[36,37,71,72]$ that strengthen conditioned responses to cocaine. Moreover, the decrease in the effects of cocaine on behavior and reward in BDNFdeficient mice suggests that the human BDNF allelic vari- 
ant underlying individual variability in BDNF expression can contribute to differences in human vulnerability to cocaine addiction [76].

\section{BDNF, Craving and Relapse in Cocaine Addiction}

One of the major clinical problems in cocaine addiction is relapse. This is often triggered by the subjective state of craving that appears during withdrawal, and precedes and accompanies drug-seeking behavior. Clinical evidence has shown that withdrawal is a critical period in addiction, during which sensitization to drug-associated environmental cues increases, triggering craving and heightening vulnerability and the risk of relapse [2]. During withdrawal, significant neuroadaptation occurs in the reward circuitry, including the molecular and cellular $[5,8,14,77,78]$ and morphological synaptic changes $[8$, 13] that have been associated with behavioral sensitization [79] and mechanisms of learning and memory [10, 80]. Recent experimental studies have suggested that changes in BDNF expression during withdrawal may mediate some of the synaptic modifications underlying the incubation of craving and subsequent relapse into drug consumption.

In experimental models of craving and relapse, responsiveness to cocaine cues increases progressively during withdrawal. In one of these studies, rats were trained to self-administer cocaine or sucrose for several days during which each reward was paired with a cue. After cocaine withdrawal, behavioral measures of lever pressing during extinction and cue-induced reinstatement of reward seeking, two different tests of cocaine craving, were progressively increased over 90 days or longer. It was found that BDNF levels rose significantly and progressively in the VTA, the NAc and the amygdala during withdrawal from cocaine, but not from sucrose. It has been suggested that increased BDNF during psychostimulant withdrawal may mediate neuronal plasticity leading to synaptic modifications that underlie enhanced responsiveness to cocaine cues and compulsive drug seeking in addicts [17]. Based on these data, the role of BDNF in cocaine withdrawal was further studied by the same laboratory in a later work using the same animal model but including an exogenous BDNF infusion into the VTA and the $\mathrm{SN}$, after the training period. Intra-VTA, but not intra-SN infusions of BDNF, progressively enhanced cocaine seeking after withdrawal. This resulted in the response to cocaine cues being higher 30 days following withdrawal from cocaine than after 3 days [20]. It is well

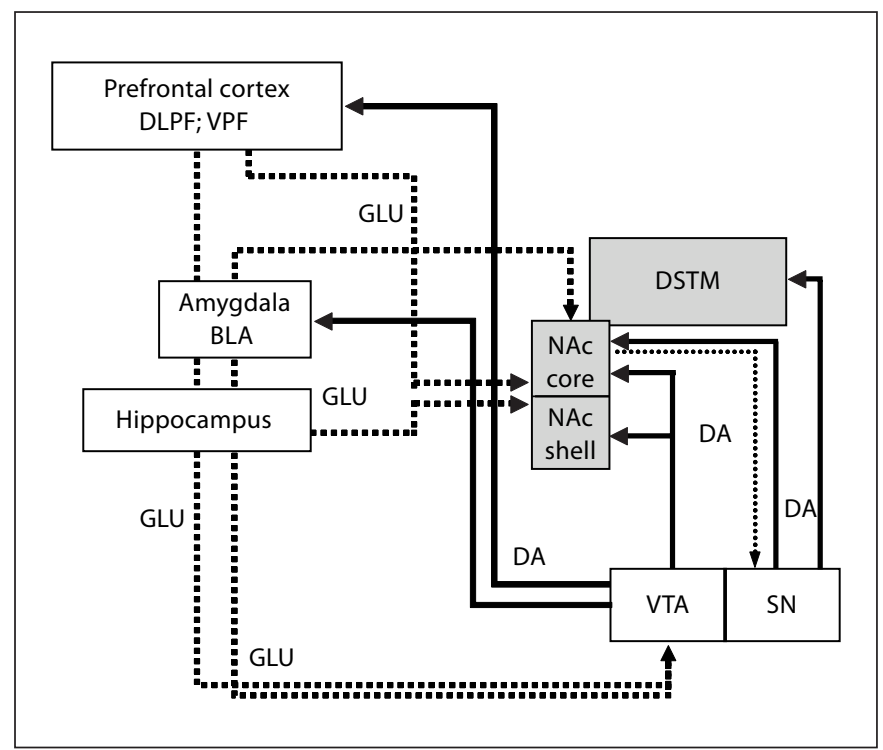

Fig. 1. Basic circuitry expressing changes in BDNF levels in cocaine addiction. It includes the primary neurotransmitters, the topographic organization and interconnections between the reward-related pathways, learning and memory pathways and circuits involved in cocaine seeking. The mesencephalic VTA projects its dopaminergic (DA) efferents to the limbic nuclei, the NAc core and shell, amygdala and hippocampus, and the dorsolateral prefrontal cortex (DLPF) and ventral prefrontal cortex (VPF). The hippocampus and amygdala, the latter through its BLA, and the DLPF and VPF project their glutamatergic (GLU) efferents to the shell and core of the NAc, respectively. The figure also includes the dorsal striatum (DSTM) and its connexions with the SN.

established that the VTA is the site of action of the primary excitatory inputs, which come from the prefrontal cortex and the amygdala (fig. 1), two regions of the brain activated by drug-associated cues [81]. The rise in BDNF levels during withdrawal may facilitate synaptic plasticity in the VTA dopamine neurons during withdrawal, which, in turn, facilitates drug-associated memory and responses to conditioned cues leading to compulsive drug seeking and relapse.

The role of BDNF in synaptic plasticity of the midbrain VTA dopamine neurons during cocaine withdrawal has been further confirmed using a neurophysiological model. In VTA slices, obtained from rats after withdrawal, weak presynaptic stimuli administered on dopamine neurons resulted in a persistent increase in excitatory postsynaptic potentials. The enhanced VTA neuronal responses were found 10-15 days after cocaine withdrawal; however, they were not detected after 1 day. This shows that, during withdrawal, VTA dopamine neurons be- 
come increasingly susceptible to the induction of LTP. At the same time, BDNF levels were found to be increased in VTA tissues after 10-15 days of withdrawal, but were not detected 1 day after withdrawal. Moreover, when exogenous BDNF was applied to the VTA before, persistent potentiation was observed both in naïve rats and after 1 day of withdrawal, suggesting that BDNF may act as a permissive factor for the induction, expression and maintenance of LTP in VTA synapses [82]. It is well established that LTP is a basic model for cellular processes that underlie information storage with the neural systems through the formation of new synapses and remodeling of the existing ones [83]. BDNF plays a critical role in modulating synaptic plasticity in learning and memory processes [36, 37, 71, 72]. Collectively, these data suggest that increased BDNF levels in VTA neurons during withdrawal may result in synaptic remodeling and sensitization which, in turn, enhance cue-associated excitatory inputs in this region of the brain contributing to compulsive drug seeking and relapse (fig. 1).

The amygdala expresses high levels of BDNF $[29,30]$ and repeated injections of psychostimulants, such as cocaine [17] or amphetamine [84], induce upregulation of BDNF expression in the basolateral nucleus of the amygdala (BLA), the medial NAc and small zones in the dorsal striatum. It is well established that the amygdala, a key structure involved in cocaine withdrawal, is a limbic nucleus which plays an important role in regulating motivational states, including those associated with addiction. Different amygdala subnuclei mediate different learning and emotional processing, and, in particular, the central nucleus of the amygdala (CeA) and the BLA have different roles in conditioned learning in drug addiction [85]. The BLA has reciprocal projections to the NAc core enabling it to influence reward-related behavior. It is accepted that the BLA is responsible for emotional Pavlovian conditioning and mediates reward-related learning, the motivational effects of emotionally significant stimuli and cue-elicited drug-seeking behavior [97]. Stimulation of the BLA can modulate the induction and maintenance of hippocampal LTP, the essential mechanism in learning and memory [86]. Taken together, these data suggest that enhanced BDNF activity following long-term abuse or dependence on psychostimulants can play an essential role in determining enduring neuroplasticity in these limbic structures (fig. 1). Such neuronal changes can account for emotional and environmental conditioned learning related to psychostimulant consumption, which can trigger a relapse even after longterm abstinence.
In humans, BDNF levels can be assessed in serum and there is evidence that serum BDNF levels correlate with levels of BDNF in the central nervous system [87]. To our knowledge, there is only one study reporting the effects of withdrawal from stimulant abuse on BDNF levels in humans. This study found significantly elevated plasma BDNF concentration in patients having a history of chronic methamphetamine abuse. These results cannot be related to the history of comorbid psychiatric illness, addiction to drugs or other organic diseases which can modify BDNF expression, because patients with such conditions were excluded. The study suggests that BDNF may play a role in the effects of methamphetamine abuse in humans [88].

\section{Intracellular Signaling Pathways of BDNF}

Through its high-affinity TrkB receptor, BDNF leads to the activation of three intracellular signal transduction systems, including the MAPK signal transduction cascade (MAPK/ERK), PI3K pathway and phospholipase [25-27] (fig. 2). It has been suggested that the role of BDNF in cocaine addiction is mediated, at least in part, through these intracellular signaling pathways.

\section{MAPK Cascade, Cocaine Addiction and Relapse}

Recent studies have demonstrated that ERK, the major effector of BDNF, is also activated by dopaminergic agonistic activity through $\mathrm{D}_{1}$ receptor $[21,58,59]$, interacting with NMDA glutamate receptors, and with a partial contribution of $\mathrm{D}_{2}$ dopamine receptors [21, 41, 89]. Since ERK is a common element for BDNF, dopamine and glutamate intracellular pathways, there appears to be a large degree of cross-talk between the signaling mechanisms and this might play a crucial role in drug addiction (fig. 2).

Acute cocaine administration induces a rapid and time-dependent increase in ERK phosphorylation (activation) in the dorsal striatum, in addition to the NAc core and shell $[58,89,90]$. Recent studies have shown that acute cocaine administration also activates ERK in other regions of the reward circuitry, including the NAc shell and core, the bed nucleus of the stria terminalis, the CeA [91, 92], the basolateral, basomedial and medial posterodorsal amygdala [92], as well as in the prefrontal cortex [92]. In addition, inhibition of ERK activity impairs the rewarding properties of acute cocaine administration [89]. 


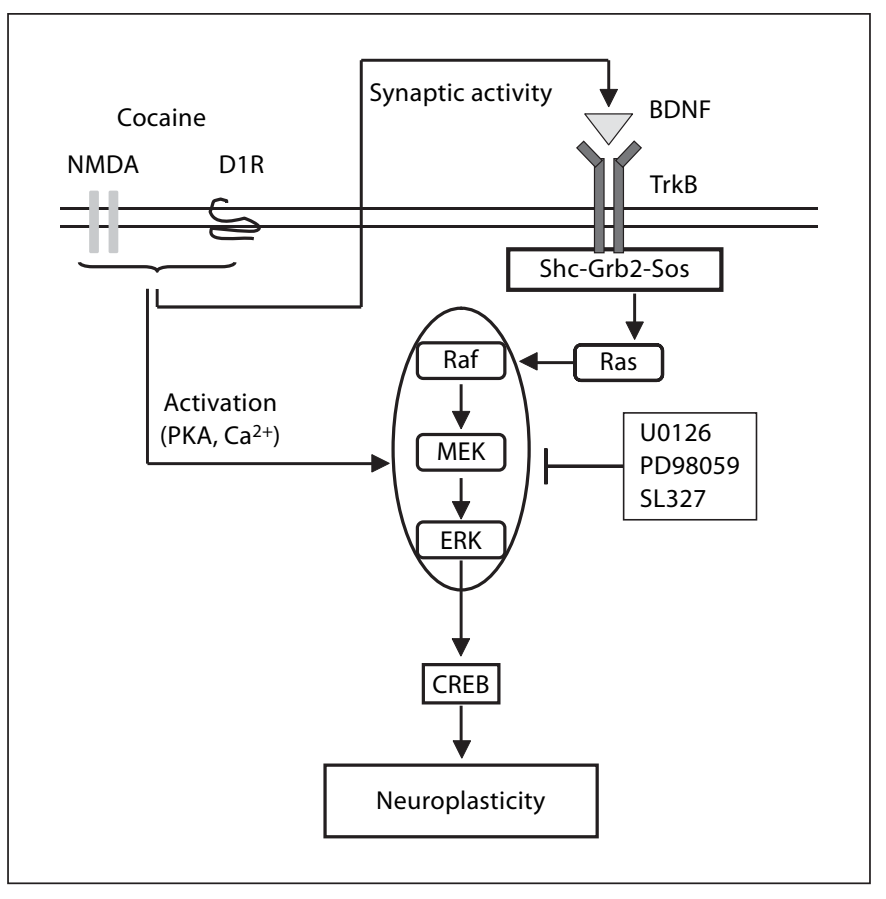

Fig. 2. BDNF and the ERK intracellular signaling pathway. The figure includes the one of the two BDNF signaling cascades involved in cocaine addiction and its interaction with dopamine and glutamate intracellular messengers. The BDNF signaling pathway is initiated by the binding of BDNF with the receptor TrkB. Once activated, the TrkB receptor autophosphorylates specific tyrosine residues within the intracellular domains. The phosphorylated tyrosines serve as protein interaction sites for Shc (SH2-containing adapter protein). Tyrosine phosphorylation of SHC subsequently triggers phosphorylation reactions that include Raf, MEK and MAPK/ERK. The cyclic AMP response element-binding protein (CREB) is an important downstream mediator for BDNF function which triggers neuronal changes and neuroplasticity. There is a cross-talk between the BDNF intracellular signaling mechanism and those of the glutamate and dopamine transmission, possibly between protein kinases (PKA) and $\mathrm{Ca}^{2+}$. U0126, PD98059 and SL327 are inhibitors of the Ras/ERK signal transduction cascade.

Chronic cocaine treatment (twice daily via intraperitoneal injection for 10 days) leads to a sustained increase in ERK activity in the VTA; however, this change was not observed in the SN, frontal cortex and NAc. Nevertheless, the increase in ERK activity in response to chronic cocaine administration was attributable to an enhanced phosphorylation state with no change in total ERK immunoreactivity. In addition, repeated BDNF infusions into the VTA induce a decrease in ERK levels with no change in ERK activity. This suggests that BDNF is able to elicit a homeostatic response in VTA cells that prevents any additional increase in ERK with repeated cocaine ad- ministration and returns ERK activity to control levels $[28,92]$. These findings support the hypothesis that BDNF, but not ERK, is also able to act as a neuroprotection factor, attenuating chronic cocaine effects by reducing the capacity of VTA neurons to respond to repeated drug exposure [28].

Based on the acute and chronic effects of cocaine on ERK activity, several authors have studied the possible role of ERK in different models of cocaine addiction. PD98059, an MAPK/ERK kinase (MEK) inhibitor, through microinjection into the VTA before repeated cocaine exposure, was used to assess the role of ERK in behavioral sensitization. Although PD98059 had no effect on the acute behavioral response, it impaired the development of behavioral sensitization after chronic cocaine administration [16]. In agreement with these results, later studies reported that SL327, another inhibitor of ERK phosphorylation, prevented locomotor sensitization and had a limited effect on the acute locomotor responses to cocaine. These reports suggested that ERK contributes only in a minor way to acute locomotor effects or to the expression of sensitized responses to psychostimulants, whereas it is crucial for the acquisition of sensitized responses $[93,94]$. Considering the role of the Ras/MAPK signal transduction cascade in neuroplasticity [95], it is possible that ERK could contribute to the neuronal changes in the NAc and VTA that are responsible for the acquisition of sensitized responses that underlies cocaine addiction in humans [94]. It is also important to consider the role of the two predominant ERK isoforms, ERK1 and ERK2, when studying the transition to cocaine addiction. Elimination of ERK1 leads to an increase in ERK2 and facilitates cocaine-induced psychomotor sensitization [93], suggesting that genetic variants that may affect the expression of these isoforms could lead to vulnerability to cocaine addiction.

During the protocol used by Valjent et al. [94] in 2006 to study cocaine sensitization, mice developed an association between the context and the effects of the drug. Animals displayed conditioned locomotor responses in the environment previously paired with cocaine, even in the absence of the drug. These conditioned locomotor responses have many similarities with Pavlovian conditioning, by which environmental cues become associated with the effects of the drug. The conditioned responses were completely abolished in mice pretreated with SL327 before each injection with cocaine, suggesting a crucial role for ERK in these responses. A CPP paradigm was used for a more detailed study of the role of ERK in the association between environmental stimuli and drug 
abuse. After behavioral conditioning was established, there was also a significant increase in ERK activity in some reward-related areas, i.e. the NAc core but not in the NAc shell [96]. The selective increase of ERK in the NAc core is consistent with the involvement of this reward region in conditioned emotional responses and in cue-elicited drug seeking $[97,98]$, while the NAc shell is involved in the unconditioned effects of cocaine [47]. The administration of intra-NAc infusions of U0126, an ERK kinase inhibitor, blocked the expression of the preference for the environment previously paired with cocaine without affecting measures of locomotion, and prevented the activation of the ERK signaling pathway. Blockade of the place preference conditioning lasted for 14 days after the injection of different MEK inhibitors [96]. Disruption of CPP induced by ERK cascade inhibitors was also reported after repeated administration of amphetamine [99] and MDMA [100]. Taken together, these findings suggested that ERK intracellular cascade in the NAc core is part of the molecular mechanisms for drug-paired contextual cue memories, by which environmental stimuli exert a motivational influence on drug-seeking behavior.

ERK is also involved in the neurobiological and behavioral changes during cocaine withdrawal, mediating the BDNF-induced potentiation of cocaine seeking in response to conditioned stimuli [20]. Inhibition of ERK phosphorylation in the CeA after 30 days of withdrawal decreased cocaine seeking in response to drug cues, while stimulation of ERK activity enhanced cocaine seeking induced by cues [101]. It has been hypothesized that the increase in ERK phosphorylation in the CeA from exposure to cocaine cues during withdrawal may be mediated by an increase in glutamate activity through the NMDA receptor [41]. These findings suggest that activation of the ERK pathway during withdrawal, in response to cocaine-conditioned cues, is involved in synaptic plasticity underlying learning and memory that results in craving and subsequent relapse. Pharmacological intervention that prevents the effects of cocaine on ERK activity should be considered in the treatment of cocaine addiction [102].

It has been hypothesized that mechanisms similar to memory reconsolidation are operating during repeated drug administration and withdrawal, and the molecular mechanism of drug-conditioned effects has been evaluated on this basis. Valjent et al. [103] reported that suppression of cocaine-induced CPP by SL327, an MEK inhibitor, required the combination of cocaine administration and the drug-associated environment and did not result from extinction. According to these results, the reactivation of drug-related memories appears to need the association of a drug injection and the conditioned drugpaired environment, in contrast to reconsolidation of other types of memories achieved by exposure to the conditioned stimulus alone. In the same study, mice were also treated with anisomycin, a protein synthesis inhibitor, after being reexposed to cocaine in the drug-paired compartment. Anisomycin abolished cocaine-induced CPP suggesting that ERK exerts its effect through protein synthesis regulation [103]. In addition, cocaine-induced locomotor sensitization cannot be reversed by cocaine reexposure in the presence of anisomycin, supporting the fact that cocaine conditioning and cocaine sensitization are two discrete behavioral responses that depend on different neurochemical mechanisms and even on different neuronal pathways [103].

\section{PI3K Cascade and Cocaine Addiction}

PI3K is a lipid kinase and a second messenger for BDNF which plays a crucial role in the cellular mechanism of LTP, being necessary for the expression of LTP, although not for its induction and maintenance $[43,44]$. PI3K can be a common pathway for the expression of multiple forms of synaptic plasticity such as dynamic modification of dendritic spines [44] and plays an important role in learning and memory [72, 104]. Recently, there has also been evidence implicating PI3K in cocaine addiction.

Cocaine-sensitized rats, treated with the reversible inhibitor of PI3K LY294002 on the challenge dose day, did not show an increase in locomotor activity. Conversely, when rats were treated with LY294002 during the initial phase of repeated cocaine administration, they showed a significant increase in locomotor activity during the cocaine challenge. These results suggested that PI3K is necessary for the expression of behavioral sensitization to cocaine but not for the induction and persistence of the sensitized behavior [105]. This is in contrast to the ERK signal transduction cascade involved in the induction of behavioral sensitization, but not in its expression $[16,94]$, suggesting that these two intracellular signaling mechanisms may play complementary roles in cocaine addiction.

Recently, the differential involvement of different brain structures in PI3K-dependent cocaine sensitization and its subsequent reversal has been evaluated. After repeated cocaine administration and withdrawal, rats showed an increase in locomotor behavior associated with enhanced p $85 \alpha /$ p110 PI3K activity in the NAc shell, 
measured after 23 days of withdrawal. Administration of pergolide (a mixed $\mathrm{D}_{1} / \mathrm{D}_{2}$ agonist)/ondansetron (a 5-HT3 selective antagonist) after withdrawal reversed behavioral sensitization and normalized the enhanced PI3K activity. At the same time, a PI3K downregulation and upregulation in the NAc core and prefrontal cortex, respectively, was reported. However, in these two regions of the brain, PI3K activity was not normalized following the reversal of cocaine sensitization. These results suggest that PI3K in the NAc shell may be one of the key alterations underlying the establishment and long-term maintenance of cocaine sensitization [106]. The discrete expression of PI3K in the NAc shell in response to cocaine sensitization and withdrawal further supports the differential roles of the NAc shell and core, with the former being involved in the expression of the sensitizing effects of cocaine [57].

\section{Conclusions}

Cocaine consumption leads to an increase in BDNF levels and enhanced activity in their intracellular pathways, ERK and PI3K, in the reward-related brain areas, including the NAc shell and core, the VTA, the CeA and BLA and even in the prefrontal cortex. These effects are especially important after several days of abstinence. BDNF, ERK and PI3K can be activated by cocaine consumption, through dopaminergic and glutamatergic stimulation, together leading to increased gene expression which plays an essential role in synaptic plasticity. The increase induced by cocaine in BDNF and its intracellular signaling mechanisms, ERK and PI3K, in the VTA, NAc shell and the prefrontal cortex may underlie sensitized responses to psychostimulants and cocaineseeking behavior after withdrawal. In the NAc core and the amygdala, the enhanced BDNF levels and ERK activity might be part of the molecular mechanisms underlying drug-paired contextual and cue memories in the context of drug-seeking behavior. All these neurochemical mechanisms could contribute to the transition from sporadic cocaine consumption to addiction and relapse even after long-term abstinence. In addition, the neurotrophin BDNF could also have some role as a protection factor in drug addiction. Finally, sensitization and memories associated with addiction to psychostimulants can be disrupted by administration of Ras/ERK and PI3K cascade inhibitors which decrease cocaine seeking after withdrawal. These results suggest potential therapeutic strategies to be explored in the context of addiction.

\section{References}

1 O'Brien CP: A range of research-based pharmacotherapies for addiction. Science 1997; 278:66-70.

$\checkmark 2$ Childress AR, Mozley PD, McElgin W, Fitzgerald J, Reivich M, O’Brien CP: Limbic activation during cue-induced cocaine craving. Am J Psychiatry 1999;156:11-18.

3 Cami J, Farre M: Drug addiction. N Engl J Med 2003;349:975-986.

-4 de Lima MS, de Oliveira Soares BG, Reisser AA, Farrell M: Pharmacological treatment of cocaine dependence: a systematic review. Addiction 2002;97:931-949.

5 Nestler EJ, Aghajanian GK: Molecular and cellular basis of addiction. Science 1997;278: 58-63.

-6 Piazza PV, Le Moal M: Glucocorticoids as a biological substrate of reward: physiological and pathophysiological implications. Brain Res Brain Res Rev 1997;25:359-372.

7 White FJ, Kalivas PW: Neuroadaptations involved in amphetamine and cocaine addiction. Drug Alcohol Depend 1998;51:141153.
8 Hyman SE, Malenka RC: Addiction and the brain: the neurobiology of compulsion and its persistence. Nat Rev Neurosci 2001;2: 695-703.

9 Robinson TE, Berridge KC: Addiction. Annu Rev Psychol 2003;54:25-53.

10 Gerdeman GL, Partridge JG, Lupica CR, Lovinger DM: It could be habit forming: drugs of abuse and striatal synaptic plasticity. Trends Neurosci 2003;26:184-192.

11 Kalivas PW, Duffy P: Time course of extracellular dopamine and behavioral sensitization to cocaine. 1. Dopamine axon terminals. J Neurosci 1993;13:266-275.

12 Kalivas PW, Volkow N, Seamans J: Unmanageable motivation in addiction: a pathology in prefrontal-accumbens glutamate transmission. Neuron 2005;45:647-650.

13 Nestler EJ: Molecular basis of long-term plasticity underlying addiction. Nat Rev Neurosci 2001;2:119-128.

14 Carlezon WA Jr, Thome J, Olson VG, LaneLadd SB, Brodkin ES, Hiroi N, Duman RS, Neve RL, Nestler EJ: Regulation of cocaine reward by CREB. Science 1998;282:22722275.
15 Altar CA, Boylan CB, Jackson C, Hershenson S, Miller J, Wiegand SJ, Lindsay RM, Hyman C: Brain-derived neurotrophic factor augments rotational behavior and nigrostriatal dopamine turnover in vivo. Proc Natl Acad Sci USA 1992;89:11347-11351.

16 Pierce RC, Pierce-Bancroft AF, Prasad BM: Neurotrophin-3 contributes to the initiation of behavioral sensitization to cocaine by activating the Ras/mitogen-activated protein kinase signal transduction cascade. J Neurosci 1999; 19:8685-8695.

17 Grimm JW, Lu L, Hayashi T, Hope BT, Su TP, Shaham Y: Time-dependent increases in brain-derived neurotrophic factor protein levels within the mesolimbic dopamine system after withdrawal from cocaine: implications for incubation of cocaine craving. J Neurosci 2003;23:742-747.

18 Filip M, Faron-Gorecka A, Kusmider M, Golda A, Frankowska M, Dziedzicka-Wasylewska M: Alterations in BDNF and trkB mRNAs following acute or sensitizing cocaine treatments and withdrawal. Brain Res 2006;1071:218-225. 
19 Horger BA, Iyasere CA, Berhow MT, Messer CJ, Nestler EJ, Taylor JR: Enhancement of locomotor activity and conditioned reward to cocaine by brain-derived neurotrophic factor. J Neurosci 1999;19:4110-4122.

-20 Lu L, Dempsey J, Liu SY, Bossert JM, Shaham Y: A single infusion of brain-derived neurotrophic factor into the ventral tegmental area induces long-lasting potentiation of cocaine seeking after withdrawal. J Neurosci 2004; 24:1604-1611.

-21 Valjent E, Pascoli V, Svenningsson P, Paul S, Enslen H, Corvol JC, Stipanovich A, Caboche J, Lombroso PJ, Nairn AC, Greengard P, Herve D, Girault JA: Regulation of a protein phosphatase cascade allows convergent dopamine and glutamate signals to activate ERK in the striatum. Proc Natl Acad Sci USA 2005;102:491-496.

$\checkmark 22$ Barde YA, Edgar D, Thoenen H: Purification of a new neurotrophic factor from mammalian brain. EMBO J 1982;1:549-553.

-23 Klein R, Nanduri V, Jing SA, Lamballe F, Tapley $\mathrm{P}$, Bryant $\mathrm{S}$, Cordon-Cardo $\mathrm{C}$, Jones KR, Reichardt LF, Barbacid M: The trkB tyrosine protein kinase is a receptor for brain-derived neurotrophic factor and neurotrophin-3. Cell 1991;66:395-403.

24 Johnson JE, Barde YA, Schwab M, Thoenen $\mathrm{H}$ : Brain-derived neurotrophic factor supports the survival of cultured rat retinal ganglion cells. J Neurosci 1986;6:3031-3038.

25 Heerssen HM, Segal RA: Location, location, location: a spatial view of neurotrophin signal transduction. Trends Neurosci 2002;25: 160-165.

-26 Kaplan DR, Miller FD: Neurotrophin signal transduction in the nervous system. Curr Opin Neurobiol 2000;10:381-391.

$\checkmark 27$ Patapoutian A, Reichardt LF: Trk receptors: mediators of neurotrophin action. Curr Opin Neurobiol 2001;11:272-280.

-28 Berhow MT, Hiroi N, Nestler EJ: Regulation of ERK (extracellular signal regulated kinase), part of the neurotrophin signal transduction cascade, in the rat mesolimbic dopamine system by chronic exposure to morphine or cocaine. J Neurosci 1996;16: 4707-4715.

-29 Gordon NS, Burke S, Akil H, Watson SJ, Panksepp J: Socially-induced brain 'fertilization': play promotes brain derived neurotrophic factor transcription in the amygdala and dorsolateral frontal cortex in juvenile rats. Neurosci Lett 2003;341:17-20.

-30 Rattiner LM, Davis M, French CT, Ressler $\mathrm{KJ}$ : Brain-derived neurotrophic factor and tyrosine kinase receptor B involvement in amygdala-dependent fear conditioning. J Neurosci 2004;24:4796-4806.

-31 Yurek DM, Lu W, Hipkens S, Wiegand SJ: BDNF enhances the functional reinnervation of the striatum by grafted fetal dopamine neurons. Exp Neurol 1996;137:105118.
32 Bland ST, Schmid MJ, Der-Avakian A, Watkins LR, Spencer RL, Maier SF: Expression of c-fos and BDNF mRNA in subregions of the prefrontal cortex of male and female rats after acute uncontrollable stress. Brain Res 2005;1051:90-99.

33 Numan S, Seroogy KB: Expression of trkB and trkC mRNAs by adult midbrain dopamine neurons: a double-label in situ hybridization study. J Comp Neurol 1999;403:295308.

34 Thoenen H: Neurotrophins and neuronal plasticity. Science 1995;270:593-598.

35 Aicardi G, Argilli E, Cappello S, Santi S, Riccio $M$, Thoenen $H$, Canossa M: Induction of long-term potentiation and depression is reflected by corresponding changes in secretion of endogenous brain-derived neurotrophic factor. Proc Natl Acad Sci USA 2004; 101:15788-15792.

36 Lee JL, Everitt BJ, Thomas KL: Independent cellular processes for hippocampal memory consolidation and reconsolidation. Science 2004;304:839-843.

37 Yamada K, Mizuno M, Nabeshima T: Role for brain-derived neurotrophic factor in learning and memory. Life Sci 2002;70:735744.

38 Ying SW, Futter M, Rosenblum K, Webber MJ, Hunt SP, Bliss TV, Bramham CR: Brainderived neurotrophic factor induces longterm potentiation in intact adult hippocampus: requirement for ERK activation coupled to CREB and upregulation of Arc synthesis. J Neurosci 2002;22:1532-1540.

39 Adams JP, Sweatt JD: Molecular psychology: roles for the ERK MAP kinase cascade in memory. Annu Rev Pharmacol Toxicol 2002. 42:135-163.

40 Curtis J, Finkbeiner S: Sending signals from the synapse to the nucleus: possible roles for CaMK, Ras/ERK, and SAPK pathways in the regulation of synaptic plasticity and neuronal growth. J Neurosci Res 1999;58:88-95.

41 Thomas GM, Huganir RL: MAPK cascade signalling and synaptic plasticity. Nat Rev Neurosci 2004;5:173-183.

42 Impey S, Obrietan K, Storm DR: Making new connections: role of ERK/MAP kinase signaling in neuronal plasticity. Neuron 1999;23:11-14.

43 Opazo P, Watabe AM, Grant SG, O’Dell TJ Phosphatidylinositol 3-kinase regulates the induction of long-term potentiation through extracellular signal-related kinase-independent mechanisms. J Neurosci 2003;23:3679_ 3688.

44 Sanna PP, Cammalleri M, Berton F, Simpson C, Lutjens R, Bloom FE, Francesconi W: Phosphatidylinositol 3-kinase is required for the expression but not for the induction or the maintenance of long-term potentiation in the hippocampal CA1 region. J Neurosci 2002;22:3359-3365
45 Martin-Iverson MT, Todd KG, Altar CA: Brain-derived neurotrophic factor and neurotrophin-3 activate striatal dopamine and serotonin metabolism and related behaviors: interactions with amphetamine. J Neurosci 1994;14:1262-1270.

46 Bassareo V, Di Chiara G: Differential responsiveness of dopamine transmission to food-stimuli in nucleus accumbens shell/ core compartments. Neuroscience 1999;89: 637-641.

$\checkmark 47$ Carlezon WA Jr, Wise RA: Rewarding actions of phencyclidine and related drugs in nucleus accumbens shell and frontal cortex. J Neurosci 1996;16:3112-3122.

48 Le Foll B, Diaz J, Sokoloff P: A single cocaine exposure increases BDNF and D3 receptor expression: implications for drug-conditioning. Neuroreport 2005;16:175-178.

49 Lauterborn JC, Rivera S, Stinis CT, Hayes VY, Isackson PJ, Gall CM: Differential effects of protein synthesis inhibition on the activity-dependent expression of BDNF transcripts: evidence for immediate-early gene responses from specific promoters. J Neurosci 1996;16:7428-7436.

50 Dluzen DE, Gao X, Story GM, Anderson LI, Kucera J, Walro JM: Evaluation of nigrostriatal dopaminergic function in adult $+/+$ and +/- BDNF mutant mice. Exp Neurol 2001; 170:121-128.

-51 Hall FS, Drgonova J, Goeb M, Uhl GR: Reduced behavioral effects of cocaine in heterozygous brain-derived neurotrophic factor (BDNF) knockout mice. Neuropsychopharmacology 2003;28:1485-1490.

52 Kalivas PW, Stewart J: Dopamine transmission in the initiation and expression of drugand stress-induced sensitization of motor activity. Brain Res Brain Res Rev 1991;16: 223-244.

53 Robinson TE, Berridge KC: The neural basis of drug craving: an incentive-sensitization theory of addiction. Brain Res Brain Res Rev 1993;18:247-291.

54 Vezina P, Lorrain DS, Arnold GM, Austin JD, Suto N: Sensitization of midbrain dopamine neuron reactivity promotes the pursuit of amphetamine. J Neurosci 2002;22:46544662.

55 Suto N, Austin JD, Tanabe LM, Kramer MK, Wright DA, Vezina P: Previous exposure to VTA amphetamine enhances cocaine selfadministration under a progressive ratio schedule in a $D_{1}$ dopamine receptor dependent manner. Neuropsychopharmacology 2002;27:970-979.

56 Pierce RC, Bari AA: The role of neurotrophic factors in psychostimulant-induced behavioral and neuronal plasticity. Rev Neurosci 2001;12:95-110.

57 Filip M, Siwanowicz J: Implication of the nucleus accumbens shell, but not core, in the acute and sensitizing effects of cocaine in rats. Pol J Pharmacol 2001;53:459-466. 
58 Zhang D, Zhang L, Lou DW, Nakabeppu Y, Zhang J, Xu M: The dopamine $\mathrm{D}_{1}$ receptor is a critical mediator for cocaine-induced gene expression. J Neurochem 2002;82:14531464.

-59 Xu M, Koeltzow TE, Santiago GT, Moratalla R, Cooper DC, Hu XT, White NM, Graybiel $\mathrm{AM}$, White FJ, Tonegawa S: Dopamine $\mathrm{D}_{3}$ receptor mutant mice exhibit increased behavioral sensitivity to concurrent stimulation of $\mathrm{D}_{1}$ and $\mathrm{D}_{2}$ receptors. Neuron 1997;19:837848 .

60 Staley JK, Mash DC: Adaptive increase in $\mathrm{D}_{3}$ dopamine receptors in the brain reward circuits of human cocaine fatalities. J Neurosci 1996;16:6100-6106.

61 Bordet R, Ridray S, Carboni S, Diaz J, Sokoloff P, Schwartz JC: Induction of dopamine $\mathrm{D}_{3}$ receptor expression as a mechanism of behavioral sensitization to levodopa. Proc Natl Acad Sci USA 1997;94:3363-3367.

-62 Guillin O, Diaz J, Carroll P, Griffon N, Schwartz JC, Sokoloff P: BDNF controls dopamine $\mathrm{D}_{3}$ receptor expression and triggers behavioural sensitization. Nature 2001;411: 86-89.

63 Di Ciano P, Underwood RJ, Hagan JJ, Everitt BJ: Attenuation of cue-controlled cocaineseeking by a selective $\mathrm{D}_{3}$ dopamine receptor antagonist SB-277011-A. Neuropsychopharmacology 2003;28:329-338.

-64 Vorel SR, Ashby CR Jr, Paul M, Liu X, Hayes R, Hagan JJ, Middlemiss DN, Stemp G, Gardner EL: Dopamine $\mathrm{D}_{3}$ receptor antagonism inhibits cocaine-seeking and cocaineenhanced brain reward in rats. J Neurosci 2002;22:9595-9603.

65 Sokoloff P, Guillin O, Diaz J, Carroll P, Griffon $\mathrm{N}$ : Brain-derived neurotrophic factor controls dopamine $\mathrm{D}_{3}$ receptor expression: implications for neurodevelopmental psychiatric disorders. Neurotox Res 2002;4: 671-678.

66 Croll SD, Wiegand SJ, Anderson KD, Lindsay RM, Nawa H: Regulation of neuropeptides in adult rat forebrain by the neurotrophins BDNF and NGF. Eur J Neurosci 1994;6:1343-1353.

-67 Mamounas LA, Blue ME, Siuciak JA, Altar CA: Brain-derived neurotrophic factor promotes the survival and sprouting of serotonergic axons in rat brain. J Neurosci 1995;15: 7929-7939.

-68 Duman RS: Pathophysiology of depression: the concept of synaptic plasticity. Eur Psychiatry 2002;17(suppl 3):306-310.

-69 Manji HK, Quiroz JA, Sporn J, Payne JL, Denicoff K, A Gray N, Zarate CA Jr, Charney DS: Enhancing neuronal plasticity and cellular resilience to develop novel, improved therapeutics for difficult-to-treat depression. Biol Psychiatry 2003;53:707-742.

-70 O’Brien CP, Childress AR, McLellan AT, Ehrman R: Classical conditioning in drugdependent humans. Ann NY Acad Sci 1992; 654:400-415.
71 Bramham CR, Messaoudi E: BDNF function in adult synaptic plasticity: the synaptic consolidation hypothesis. Prog Neurobiol 2005; 76:99-125.

72 Yamada K, Nabeshima T: Brain-derived neurotrophic factor/TrkB signaling in memory processes. J Pharmacol Sci 2003;91:267270.

73 Hall J, Thomas KL, Everitt BJ: Rapid and selective induction of BDNF expression in the hippocampus during contextual learning. Nat Neurosci 2000;3:533-535.

74 Rattiner LM, Davis M, Ressler KJ: Brain-derived neurotrophic factor in amygdala-dependent learning. Neuroscientist 2005; 11: 323-333.

75 Le Foll B, Frances H, Diaz J, Schwartz JC, Sokoloff $\mathrm{P}$ : Role of the dopamine $\mathrm{D}_{3}$ receptor in reactivity to cocaine-associated cues in mice. Eur J Neurosci 2002;15:2016-2026.

76 Uhl GR, Liu QR, Walther D, Hess J, Naiman $\mathrm{D}$ : Polysubstance abuse-vulnerability genes: genome scans for association, using 1,004 subjects and 1,494 single-nucleotide polymorphisms. Am J Hum Genet 2001;69:12901300.

77 Koob GF, Le Moal M: Drug abuse: hedonic homeostatic dysregulation. Science 1997; 278:52-58.

78 Koob GF, Le Moal M: Plasticity of reward neurocircuitry and the 'dark side' of drug addiction. Nat Neurosci 2005;8:1442-1444.

79 Pierce RC, Kalivas PW: A circuitry model of the expression of behavioral sensitization to amphetamine-like psychostimulants. Brain Res Brain Res Rev 1997;25:192-216.

80 Fuchs RA, Feltenstein MW, See RE: The role of the basolateral amygdala in stimulus-reward memory and extinction memory consolidation and in subsequent conditioned cued reinstatement of cocaine seeking. Eur J Neurosci 2006;23:2809-2813.

81 Kauer JA: Learning mechanisms in addiction: synaptic plasticity in the ventral tegmental area as a result of exposure to drugs of abuse. Annu Rev Physiol 2004;66:447475.

82 Pu L, Liu QS, Poo MM: BDNF-dependent synaptic sensitization in midbrain dopamine neurons after cocaine withdrawal. Nat Neurosci 2006;9:605-607.

83 Geinisman Y: Structural synaptic modifications associated with hippocampal LTP and behavioral learning. Cereb Cortex 2000;10: 952-962.

84 Meredith GE, Callen S, Scheuer DA: Brainderived neurotrophic factor expression is increased in the rat amygdala, piriform cortex and hypothalamus following repeated amphetamine administration. Brain Res 2002; 949:218-227.

85 Everitt BJ, Parkinson JA, Olmstead MC, Arroyo $\mathrm{M}$, Robledo $\mathrm{P}$, Robbins TW: Associative processes in addiction and reward. The role of amygdala-ventral striatal subsystems. Ann NY Acad Sci 1999;877:412-438.
86 Frey S, Bergado-Rosado J, Seidenbecher T, Pape HC, Frey JU: Reinforcement of early long-term potentiation (early-LTP) in dentate gyrus by stimulation of the basolateral amygdala: heterosynaptic induction mechanisms of late-LTP. J Neurosci 2001;21:36973703.

87 Karege F, Schwald M, Cisse M: Postnatal developmental profile of brain-derived neurotrophic factor in rat brain and platelets. Neurosci Lett 2002;328:261-264.

88 Kim DJ, Roh S, Kim Y, Yoon SJ, Lee HK, Han CS, Kim YK: High concentrations of plasma brain-derived neurotrophic factor in methamphetamine users. Neurosci Lett 2005;388: 112-115.

89 Valjent E, Corvol JC, Pages C, Besson MJ, Maldonado R, Caboche J: Involvement of the extracellular signal-regulated kinase cascade for cocaine-rewarding properties. J Neurosci 2000;20:8701-8709.

90 Jenab S, Festa ED, Nazarian A, Wu HB, Sun WL, Hazim R, Russo SJ, Quinones-Jenab V: Cocaine induction of ERK proteins in dorsal striatum of Fischer rats. Brain Res Mol Brain Res 2005;142:134-138.

91 Radwanska K, Caboche J, Kaczmarek L: Extracellular signal-regulated kinases (ERKs) modulate cocaine-induced gene expression in the mouse amygdala. Eur J Neurosci 2005; 22:939-948.

92 Valjent E, Pages C, Herve D, Girault JA, Caboche J: Addictive and non-addictive drugs induce distinct and specific patterns of ERK activation in mouse brain. Eur J Neurosci 2004;19:1826-1836.

93 Ferguson SM, Fasano S, Yang P, Brambilla R, Robinson TE: Knockout of ERK1 enhances cocaine-evoked immediate early gene expression and behavioral plasticity. Neuropsychopharmacology 2006;31:2660-2668.

$\checkmark 94$ Valjent E, Corvol JC, Trzaskos JM, Girault JA, Herve D: Role of the ERK pathway in psychostimulant-induced locomotor sensitization. BMC Neurosci 2006;7:20.

$>95$ Sweatt JD: Mitogen-activated protein kinases in synaptic plasticity and memory. Curr Opin Neurobiol 2004;14:311-317.

96 Miller CA, MarshallJF: Molecular substrates for retrieval and reconsolidation of cocaineassociated contextual memory. Neuron 2005; 47:873-884.

$\checkmark 97$ Cardinal RN, Parkinson JA, Lachenal G, Halkerston KM, Rudarakanchana N, Hall J, Morrison CH, Howes SR, Robbins TW, Everitt BJ: Effects of selective excitotoxic lesions of the nucleus accumbens core, anterior cingulate cortex, and central nucleus of the amygdala on autoshaping performance in rats. Behav Neurosci 2002;116:553-567.

$\checkmark 98$ Ito R, Dalley JW, Howes SR, Robbins TW, Everitt BJ: Dissociation in conditioned dopamine release in the nucleus accumbens core and shell in response to cocaine cues and during cocaine-seeking behavior in rats. J Neurosci 2000;20:7489-7495. 
99 Gerdjikov TV, Ross GM, Beninger RJ: Place preference induced by nucleus accumbens amphetamine is impaired by antagonists of ERK or p38 MAP kinases in rats. Behav Neurosci 2004;118:740-750.

100 Salzmann J, Marie-Claire C, Le Guen S, Roques BP, Noble F: Importance of ERK activation in behavioral and biochemical effects induced by MDMA in mice. Br J Pharmacol 2003;140:831-838

101 Lu L, Hope BT, Dempsey J, Liu SY, Bossert JM, Shaham Y: Central amygdala ERK signaling pathway is critical to incubation of cocaine craving. Nat Neurosci 2005;8:212219.
102 Lu L, Koya E, Zhai H, Hope BT, Shaham Y: Role of ERK in cocaine addiction. Trends Neurosci 2006;29:695-703.

103 Valjent E, Corbille AG, Bertran-Gonzalez J, Herve D, Girault JA: Inhibition of ERK pathway or protein synthesis during reexposure to drugs of abuse erases previously learned place preference. Proc Natl Acad Sci USA 2006;103:2932-2937.

104 Mizuno M, Yamada K, Takei N, Tran MH, He J, Nakajima A, Nawa H, Nabeshima T: Phosphatidylinositol 3-kinase: a molecule mediating BDNF-dependent spatial memory formation. Mol Psychiatry 2003;8:217224.
105 Izzo E, Martin-Fardon R, Koob GF, Weiss F, Sanna PP: Neural plasticity and addiction: PI3-kinase and cocaine behavioral sensitization. Nat Neurosci 2002;5:12631264.

106 Zhang X, Mi J, Wetsel WC, Davidson C, Xiong X, Chen Q, Ellinwood EH, Lee TH: PI3 kinase is involved in cocaine behavioral sensitization and its reversal with brain area specificity. Biochem Biophys Res Commun 2006;340:1144-1150. 